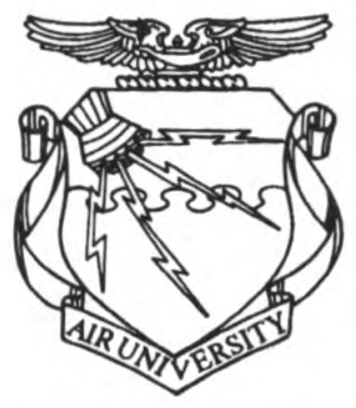

\title{
In the Aftermath of War US Support for Reconstruction and Nation-Building in Panama Following Just Cause
}

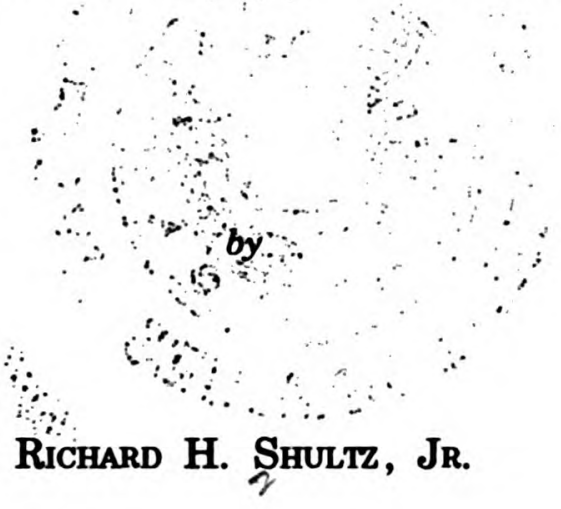

Air University Press 401 Chennault Circle

Maxwell Air Force Base, Alabama 36112-6428 